\title{
Epistemologia do território: a prostituição masculina em Goiânia
}

\author{
Territorial epistemology: male prostitution in Goiânia
}

Valdir Inácio do Prado Júnior, Fabrício Borges do Amaral, Ycarim Melgaço Barbosa

Pontifícia Universidade Católica de Goiás (PUC-GO), Goiânia, GO, Brasil

\section{Resumo}

Este artigo tem como objetivo analisar a interação entre os diferentes territórios de prostituição masculina em Goiânia, Estado de Goiás, e os conceitos basilares referentes ao assunto. Para tanto, foram adotadas como metodologia as pesquisas bibliográfica e qualitativa. Por meio do levantamento bibliográfico, foi feito um mapeamento do território e de suas concepções no âmbito da Geografia e de outras áreas do conhecimento. Além disso, procedeu-se a uma entrevista semiestruturada com quatro participantes, na qual foram relatadas observações a respeito da prostituição masculina. Nota-se que os territórios fazem parte de um contexto mais amplo, não se restringindo ao espaço geográfico. Nesse contexto, encontram-se a imagem, o texto e o corpo. Goiânia contempla territórios fixos de prostituição, compreendendo um quadrilátero no Setor Central da cidade, onde são encontrados os chamados acompanhantes e seus territórios simbólicos e móveis. Assim sendo, como resultado da pesquisa, foram identificadas a movimentação e a formação de pontos móveis e simbólicos na região citada. Com relação ao ponto fixo, este ocorre em horários não comerciais.

Palavras-chave: Goiânia. Prostituição masculina. Territorialidade. Território.

\section{Abstract}

This article aims to analyze the interaction among the different territories of male prostitution in Goiânia, state of Goiás, and the basic concepts regarding the subject. For that purpose, we adopted as methodology both bibliographic and qualitative researches. Through a bibliographic survey, we mapped the territory, along with its conceptions within the scope of Geography and other areas of knowledge. Four participants answered a structured interview reporting observations about male prostitution. We observed that territories are part of a broader context, not restricted to geographic areas, including image, text and body. Goiânia has fixed prostitution territories, comprised of a quadrangle in the city's Central neighborhood. In this area, the so-called male escorts and their symbolic and mobile territories are found. Hence, this research identified the movement and the formation of mobile and symbolic spots in the abovementioned region. Fixed spots occur during non-business hours.

Keywords: Goiânia. Male prostitution. Territoriality. Territory.

VIPJ é bacharel em Análise de Sistemas, mestre em Desenvolvimento e Planejamento Territorial, e-mail: valdirpradojr@gmail.com FBA é bacharel em Direito, mestre em Desenvolvimento e Planejamento Territorial, e-mail: fbaconsultores@gmail.com YMB é bacharel em Direito, doutor em Geografia, e-mail: ycarim@gmail.com 


\section{Introdução}

A reflexão acerca dos diferentes tipos de território é importante para a composição do estudo sobre as questões territoriais. A territorialização, a desterritorialização, a reterritorialização, a multiterritorialização e a microterritorialidade são composições essenciais no desenvolvimento e no planejamento territorial.

Este artigo tem por objetivo fazer o levantamento de vários territórios que emergem a partir de tantas definições, o que envolve questões antropológicas de territorialidades simbólicas, móveis, culturais e econômicas, vinculadas a uma nova concepção do território do corpo, da rua e das mídias. Portanto, intenta-se aqui fazer um levantamento sobre os territórios da cidade de Goiânia, capital do Estado de Goiás, onde se encontra a prostituição masculina, e verificar a interação entre esses territórios.

Entendendo a relevância do tema e o anseio em contribuir com a literatura e a pesquisa sobre a prostituição masculina, nota-se que essa ocupação está assentada na sociedade goianiense, mas escondida em seus meandros. Não há ainda a regulamentação dessa atividade como profissão, mas os direitos e os deveres dos acompanhantes são amparados pela legislação, principalmente quando se toma em consideração a Consolidação das Leis Trabalhistas (Brasil, 1943) e o próprio Código Civil (Brasil, 2002). Diante disso, compete ao pesquisador verificar como se formam esses territórios em Goiânia.

\section{Metodologia}

Este estudo amparou-se em pesquisas de caráter bibliográfico e qualitativo. Inicialmente, pretendeu-se mapear os vários campos de conhecimento que abordam a temática "território" a fim de elucidar os territórios da prostituição masculina. Desse modo, foram realizadas buscas no portal de periódicos da Coordenação de Aperfeiçoamento de Pessoal de Nível Superior (CAPES)/Ministério da Educação (MEC), utilizando diversos bancos de dados, a saber: PycInfo, Scielo, Lilacs, Scopus e Onefile. Os descritores empregados foram: "territórios", "corpo" e "prostituição". Ao todo, foram levantados 140 artigos, dos quais apenas 39 se aproximaram do tema de pesquisa, não tratando, contudo, dos constructos território e prostituição em Goiânia. Em outras palavras, não foram encontrados instrumentos que avaliassem o território, relacionados diretamente com a prostituição masculina, o que fomenta ainda mais a perspectiva de um espaço amplo de estudo e pesquisa. Ademais, foram pesquisados 45 livros da área de desenvolvimento regional e dois sites governamentais (Ferreira, 2002).

Logo após, foi construído um questionário semiestruturado com o objetivo de levantar dados acerca da prostituição masculina em Goiânia. Nos meses de novembro e de dezembro de 2016, foram entrevistados quatro garotos de programa, com idade média de 26 anos.

\section{Território: local de trabalho}

Ao abordar o conceito de território, Foucault (2008) o contextualiza não somente em termos geográficos, mas também políticos e jurisprudenciais, evidenciando as relações de poder e como elas são aplicadas, tanto física quanto verbalmente. Nesse sentido, o território se une a vários campos, quer epistemologicamente, quer nas vastas áreas das Ciências Sociais, promovendo espaço, características econômicas e, principalmente, determinando a vida da sociedade. Observa-se então que "[...] os territórios tornam-se elementos da genealogia dos processos, conferindo-lhes uma natureza incerta, contingente e inesperada" (Reis, 2015, p. 109). Dessa forma, pode-se afirmar que território ultrapassa as barreiras geográficas, internalizando uma cultura no espaço e os valores de um povo (Gondim \& Monken, 2008; Castro, 2009).

Esse conceito tem origem nas ciências naturais, em que os animais e as plantas condicionam seus territórios pela dominação de determinada região física. Essa ideia foi incorporada pela Geografia, área de estudo que estabeleceu as relações de espaço e os limites geográficos, promovendo, assim, as relações de poder instituídas dentro dos territórios. Com base na ideia de poder, outras áreas do conhecimento incorporaram esse conceito, como a Sociologia, a Antropologia, a Economia, a Ciência Política, o Direito e a Psicologia (Flores, 2006; Haesbaert, 2014).

Nota-se que o termo "território" também estabelece vínculo com a ideia de nação, carregado de relações sociais, com foco econômico. Nesse sentido, o mercado, a moeda, a população e o próprio território estabelecem uma relação de força maior, o que dá origem à nação, a qual pode originar outras, romper-se ou até mesmo 
dividir-se (Ianni, 1988; Haesbaert, 2014). Além disso, observa-se que fragmentos da população de uma nação podem estabelecer fronteiras imaginárias, antropológicas e, sobretudo, mercadológicas.

Território não é sinônimo de espaço, ainda que, para alguns, ambas as palavras apresentem o mesmo significado. Do mesmo modo territorialidade e espacialidade não devem ser empregadas de modo indiferenciado. Etimologicamente, território deriva do latim terra e torium, significando terra pertencente a alguém. Pertencente, entretanto, não se vincula necessariamente à propriedade da terra, mas a sua apropriação. Essa apropriação, por sua vez, tem um duplo significado. De um lado, associa-se ao controle de fato, efetivo, por vezes legitimado por parte de instituições ou grupos sobre um dado segmento do espaço. Neste sentido o conceito de território vincula-se à geografia política e à geopolítica. A apropriação, por outro lado, pode assumir uma dimensão afetiva, derivada das práticas especializadas por parte de grupos distintos definidos segundo renda, raça, religião, sexo, idade ou outros atributos. Neste sentido o conceito de território vincula-se a uma geografia que privilegia os sentimentos e simbolismos atribuídos aos lugares. [...] Apropriação passa associar-se à identidade de grupos e à afetividade espacial (Corrêa, 1994, p. 251).

0 território, enquanto terra, não pode se restringir ao espaço físico, uma vez que representa as características de uma sociedade e seus limites estabelecidos pelo poder, tendo sua propriedade controlada pelo grupo que nele está inserido. Isso contempla os seres humanos, os animais e os vegetais de determinada localidade. E, além disso, contempla a cultura, a sociedade, a geografia, a política, a economia e os fatores psicológicos de um grupo (Geiger, 1994).

Quando se fala em território, observa-se um conjunto de diferentes interpretações, seja por meio de uma visão meramente estática, seja por uma mais complexa, norteada por questões culturais, políticas e econômicas. Todas essas questões são organizadas hierarquicamente, estabelecendo relações de poder que controlam e determinam as relações humanas (Raffestin, 1993; Gehlen \& Riella, 2004).
[...] 0 território é visto como um espaço delimitado e controlado, através do qual se exerce um determinado poder, na maioria das vezes - mas não exclusivamente - relacionado ao poder político do Estado. [...] 0 território é visto, sobretudo, como o produto da apropriação/valorização simbólica de um grupo em relação ao seu espaço vivido. [...] território como fonte de recursos e/ou incorporado no embate entre classes sociais e na relação capital-trabalho, como produto da divisão "territorial" do trabalho, por exemplo. [...] território com base nas relações entre sociedade e natureza, especialmente no que se refere ao comportamento "natural" dos homens em relação ao seu ambiente físico (Haesbaert, 2004, p. 40).

De acordo com Saquet (2007), o território é a soma de vários elementos - econômicos, políticos e culturais - , que são fundamentais para a compreensão acerca das mudanças que ocorrem no território, em especial da percepção que a sociedade tem desse tempo e espaço. Nesse sentido, o território assume dimensões de interação das relações de poder controladas pelo Estado, que determina a noção de espaço e de território. Contudo, a Antropologia trata das questões simbólicas; a Sociologia, da intervenção das relações; e a Psicologia, da construção da subjetividade. Observa-se então que territorialidade assume uma multidisciplinaridade, abrangendo terra, poder e relações humanas (Haesbaert, 2004; Vilela, 2009).

A par dessas considerações, verifica-se a interação entre os aspectos sociais e as relações estabelecidas no comércio do sexo, assim como um público diferenciado nos variados locais de divulgação desse "produto". Por exemplo, detecta-se, dentro de determinado grupo, usuários de drogas, que são os que mais se expõem nas ruas a fim de conseguirem dinheiro para comprar mais drogas. Esse é um exemplo de formação de territórios sociológicos e psicológicos (Souza \& Carvalho, 2014). 0 território também pode ser delimitado por perspectivas econômicas, pois dentro dele se desenvolvem vários tipos de economia, articulando o saber fazer com a cultura do local.

Na presente pesquisa, observou-se, durante a análise das informações, que há uma região fragmentada no quadrilátero do Setor Central da cidade de Goiânia, compreendendo as ruas 2, 8, 3 e 7. Essa localidade é percebida pelos moradores da cidade de Goiânia, por clientes e, inclusive, pelos próprios garotos de 
programa como ponto fixo de prostituição masculina no período noturno. Identificou-se também que os acompanhantes cobram por hora de atendimento, e o valor varia de $R \$ 50,00$, cobrados nas ruas e saunas masculinas, a R\$300,00, para atendimento em local próprio ou em domicílio. A quantidade de atendimentos realizados oscila, pois está ligada diretamente ao local e ao estereótipo do território-corpo (Flores, 2006; Castro, 2008; Pompei et al., 2014). Fica latente essa região do quadrilátero nas próprias observações do participante 3, quando afirma que o local sempre foi ponto de prostituição masculina: "[...] aqui é tão conhecido que as pessoas chamam de feira do sexo". Notase também que determinados grupos se aglomeram de acordo com sua própria estereotipagem, e os clientes escolhem de acordo com a imagem física que cada grupo passa, incluindo, muitas vezes, o órgão sexual.

Corrêa (1994) e Geiger (1994) afirmam que os territórios possuem áreas de livre acesso e circulação, abertas ao público, o que promove diferentes relações lúdicas, com aglomerações de serviços centrais de variadas áreas. Estas são utilizadas para que a população desfrute do ambiente como forma de agregar valor e renda.

Durante a pesquisa, observou-se que os garotos de programa e os clientes promovem encontros em determinados locais com objetivo apenas sexual, como pontuou um dos entrevistados: "A gente junta todo mundo em determinados dias no mês para uma tremenda de uma suruba". Nesse sentido, verifica-se a criação de uma microterritorialidade, pois esse novo evento criado, mesmo sendo em outro espaço, representa uma continuidade dos espaços já delimitados na rua (Fortuna, 2012).

Desde o século passado, existe uma preocupação com o controle do território realizado pelo Estado e com as relações estabelecidas dentro desse espaço. Logo, é imprescindível entender a origem dos termos "território", "territorialidade”, "desterritorialidade" e "microterritorialidade", bem como suas influências nas Ciências Sociais, que fazem uso desses conceitos, em especial a geografia política e a geopolítica. Esses conceitos estão vinculados à ideia de poder, sendo a área dominada ou gerida por determinado grupo. Portanto, torna-se um equívoco reduzir esses termos à ideia de espaço ou de lugar (Andrade, 1994; Haesbaert, 2014).
Acerca da prostituição masculina, a simbologia e a mobilidade podem ser identificadas nas ruas onde ela está inserida, bem como nas mídias: nos classificados dos jornais, nas páginas publicitárias na internet e nos aplicativos para telefones móveis.

Nesse contexto, importa mencionar a desarmonia entre o território local e o território de todos, devido a ideologias, regras, crenças e culturas. Isso porque se tem a sociedade com suas características regionais: o comércio nas ruas, instalado no local onde se situam os microterritórios dessa prostituição, e a sociedade migratória temporária. Assim, destaca-se o compartilhamento solidário dos membros que compõem esse novo território, com o cruzamento de suas regras locais, estimulando a territorialidade, ou seja, criando engajamento, dedicação e integração (Santos et al., 1994; Andrade, 1994).

0 território simbólico é considerado abstrato. Nele, há contradições, disparidades, choques e territórios sobrepostos. Em determinados momentos, é ocupado por um grupo; em outro, esse mesmo território é ocupado por um grupo diferente do anterior, ocasionando, desse modo, a reterritorialização. Importa mencionar também as relações sociais estabelecidas dentro dos territórios, sendo elas relevantes para o estudo da territorialidade humana, tornando um arquétipo nas novas formas de repensá-lo (Raffestin, 1987, 1993).

Na região central de Goiânia, no período diurno, encontra-se o comércio local; ao se desterritorializar, ou seja, quando o comércio fecha suas portas, o local se reterritorializa com uma nova atividade, a da prostituição. Entram em cena os acompanhantes, que desfilam pelas ruas a fim de venderem seus corpos, com suas simbologias peculiares, recriando esse território delimitado por fronteiras imaginárias.

Por meio da reterritorialização, cria-se um novo ambiente; emerge da escuridão um mundo diferenciado. Os acompanhantes tentam chamar a atenção dos clientes que transitam pelo local, até que estes escolham os que mais lhe agradam. Verifica-se que os acompanhantes realizam a abordagem na própria rua a fim de comercializarem seu corpo. A consumação do ato sexual ocorre, muitas vezes, dentro do próprio veículo do cliente, nas ruas desertas da região, em hotéis e motéis locais ou em outras regiões.

Segundo Santos et al. (1994), o território é a forma de mostrar ao mundo sua coesão, sua finalidade, seus processos naturais e os comportamentos da sociedade em seu respectivo espaço. Pode ser considerado território 
móvel em função do movimento e da criação de um novo lugar, ligado de maneira vertical ou horizontal, virtual ou física, pela proximidade ou distância, sendo formado por uma rede de comunicação vinculada aos seus paradigmas sociais. Essa rede promove uma nova realidade, a qual constituirá um percentual do espaço unido por diversas partes.

Nota-se que há uma consciência mútua dos usuários desses espaços, visto que estabelecem uma interação social entre si; isso, consequentemente, dá origem a regras de conduta. Em outras palavras, na rua, devem-se respeitar o seu limite e o limite do outro, visto que o corpo é exposto como mercadoria. Já nas mídias (jornais, sites e aplicativos), os acompanhantes seguem um padrão de como divulgarem o corpo, formando, assim, a territorialidade do grupo (Goffman, 2010).

Quando se fala em território, não se pode deixar de abordar as pessoas que vivem e usufruem de determinados espaços. No território, condições de poder diferenciadas são necessárias para a sobrevivência desses indivíduos, ou seja, normas são projetadas, mas não as do próprio território, que foram estabelecidas anteriormente, e sim as criadas pelas pessoas que o habitam (Sack, 1986; Santos et al., 1994). Nesse sentido, é mister compreender a territorialidade a fim de verificar as dinâmicas estabelecidas entre os indivíduos que estão inseridos no território, seja por controle de recursos, seja por pessoas (Sack, 1986).

A territorialidade humana é uma ideia secundária da área da Geografia. Em seu sentido etológico, o termo "territorialidade" remete à concepção dos limites dos territórios dos animais, transferindo ideia símile à ciência dos homens. Nesse sentido, Raffestin (1987, p. 264) entende que o ser humano

[...] é um animal semiológico cuja territorialidade é condicionada por linguagens, códigos e sistemas de sinais. 0 procedimento do homem, de alguma forma, está na constituição linguística do mundo.

Durante o desenvolvimento deste estudo, constatou-se uma linguagem corporal própria dos acompanhantes, mediante gesticulações e exposição da imagem enquanto produto, bem como formas de posicionamento, isto é, os corpos desses indivíduos relacionam-se com os outros, com o objetivo de delimitar o espaço dentro do território, pois o próprio corpo precisa ter uma relação recíproca com o espaço onde está inserido. Ao vincular o corpo a questões geográficas - consequentemente, territoriais percebe-se a inclusão desses indivíduos dentro de um mundo social, fazendo com que se insiram em uma posição específica no espaço (Barthe-Deloizy, 2011).

Ao estabelecer uma comparação entre os territórios animal e humano, nota-se que o primeiro limita-se ao espaço, enquanto o segundo vincula-se à cultura e à comunicação. Diante disso, entende-se que a territorialidade humana consiste em relações estabelecidas entre os seres humanos, inseridos em uma sociedade com diversidades específicas, tais como línguas, religiões, tecnologias, atitudes, afinidades, consistindo em constante entrada e saída de território, ou seja, territorialização, desterritorialização e reterritorialização (Raffestin, 1987).

Importa mencionar que a principal característica do processo de territorialização é o impacto econômico. Ao extinguir as fronteiras do território ou quando elas são deixadas para trás pela sociedade, tem-se a desterritorialização; quando se retoma ou se reconstrói o território com base em fatores econômicos, tem-se a reterritorialização (Raffestin, 1993).

Segundo Corrêa (1994), a territorialidade consiste em um conjunto de costumes e de simbologias dos grupos sociais; a desterritorialização, por sua vez, é entendida como eliminação da sociedade que se desfaz de seu território, promovendo novas territorialidades. A desterritorialização não exaure o território, pois trata da forma como este é utilizado a fim de descrever os movimentos dos objetos para novas localidades, ou seja, deslocamentos abstratos e concretos, vinculados ou não à geografia, promovendo ligações entre a sociedade e o seu novo território (Guattari, 1990).

Pode-se afirmar que a territorialidade é promovida pelos fetiches, estabelecidos por uma relação social quimérica, ou seja, ilusória. Marx \& Engels (1980) destacam que fetiches são produtos imaginários, criados pelo cérebro carregado de fantasias. Porém, eles possuem vidas próprias, assim como os preconceitos. Nesse sentido, observa-se que a prostituição masculina, escondida nos meandros da sociedade, gera medo, repulsa e até mesmo agressividade dentro do grupo, pois não é algo considerado comum. Todavia, nessas territorialidades, formam-se ideias, valores, culturas e ideologias. No entanto, a desterritorialização é considerada a migração do poder de um espaço para outro, podendo gerar conflitos sociais, mas com os mesmos valores ligados à territorialidade. Já a reterritorialização, ou nova territorialidade, é a 
fixação daquilo que foi desterritorializado por meio de lutas sociais, podendo também ser caracterizada pelo novo enraizamento de movimentos migratórios, grupos informais, ilegais, indústrias do sexo, entre outros, os quais promovem um novo urbanismo nos locais que fixarão como novo território (Neves, 1994; Barreto, 2008).

Analisando a literatura existente sobre o tema, Braz (2011) destaca que a prostituição remonta aos povos caldeus, visto que era costume entre eles oferecer suas mulheres e filhas aos visitantes como forma de mostrar hospitalidade. 0 caráter profano dessa prática é que a caracterizava como prostituição, visto que, do ponto de vista cultural e social, era uma prática aceitável. Nos dias atuais, a prostituição é utilizada para a satisfação de desejos sexuais, principalmente da fantasia. Portanto, comercializar o corpo também atinge a ânsia do prazer, em que o fetichismo está ligado à perpetuação do consumo e à necessidade de se obter a mercadoria.

Harvey (2001) afirma que uma estética predefinida insere, no imaginário humano, o fetiche como um objeto de anseio, em que o anúncio do produto nos territórios móveis e simbólicos, como jornais, sites e aplicativos, aguça a curiosidade dos clientes. Nesse sentido, verifica-se que os acompanhantes tentam estabelecer a relação sexo-mercadoria-cliente, sendo eles responsáveis por atender aos desejos e realizar as fantasias daqueles que utilizam seus serviços (Figueiredo et al., 2003; Henrique, 2009; Haesbaert, 2014).

Com relação à rua, Dicionário Michaelis (2009) a define como um local público rodeado por muros, casas, prédios, praças, comércios, dentro das cidades, das vilas e dos vilarejos. Assim sendo, as cidades estão inseridas em um espaço que possuem fronteiras. Medeiros (1999) afirma que a rua pode ser vista como uma categoria social; nela, está inserido um território de vida e de trabalho, resultando em um processo social de exploração, de predominância e de exclusão. Oliveira (1998) destaca que a rua é segmentada de espaços de caráter prolífico, doutrinador, emblemático, violento, que recria, reorganiza e concebe territórios carregados de aspectos morais. Esse território operacionaliza os efeitos públicos e financeiros dos habitantes dos espaços construídos ou não, “[...] o lugar do não lugar" (Oliveira, 1998, p. 51).

Todavia, as ruas possuem características profanas e habitantes carregados de ideologias, que buscam resguardar sua dignidade e seu senso social. De um lado, considerada como um espaço maléfico carregado de tendências libidinosas, enxergada como um espaço de imoralidade; de outro, o reflexo de uma sociedade sem medo, onde há festividades, comemorações, movimentos, uma rede produtiva de trabalho, com características identitárias variadas, multifacetada, cheia de ideologias sociais e exequibilidades distintas (Oliveira, 1998).

Nesse território, considerado o lugar de todos, verificam-se movimentos que caracterizam os territórios móveis por meio das várias atividades desenvolvidas, pela volubilidade do que ocorre nos turnos e pelo comércio estabelecido por diferentes grupos que buscam um serviço determinado. Nesse sentido, importa destacar a disputa de forças travada entre os diferentes grupos sociais presentes nesses lugares, em que o mais forte domina o mais fraco ou aquele que não se organizou em grupo, promovendo as diferentes territorialidades. Dessa forma, pode-se afirmar que territorialidade é a aglomeração de comportamentos com características comuns entre os indivíduos (Oliveira, 1998; Haesbaert, 2014).

Com relação à demarcação das fronteiras, invisíveis nos espaços públicos, esta acontece de forma simbólica, estabelecendo a relação entre direção no espaço e legitimação de sua posse. Assim, a apropriação de alguns logradouros, na área central ou periférica da cidade, existe em função de suas particularidades, o que contribui, dessa forma, para originar determinados territórios de prostituição masculina (Ribeiro \& Mattos, 1996; Haesbaert, 2014).

0 território estudado nesta pesquisa restringe-se à cidade de Goiânia, considerada umas das mais modernas e com grande relevância econômica para o Centro-Oeste. A localização geográfica de Goiás coloca o Estado em uma posição logística estratégica, pois se situa no centro do país e conta com uma malha rodoviária que interliga as demais regiões do Brasil. De acordo com a Secretaria do Estado de Gestão e Planejamento (Goiás, 2013), em um raio de aproximadamente $1.200 \mathrm{~km}$, localizam-se aproximadamente $75 \%$ do mercado consumidor do país. Em outras palavras, o Estado de Goiás está situado em um ponto estratégico, com acesso rápido às capitais de São Paulo, Rio de Janeiro, Minas Gerais e à capital federal, Brasília.

Em Goiânia, os limites imaginários demarcados simbolicamente configuram-se em territórios noturnos fixos, sendo estes considerados também territórios 
móveis, devido à transformação diurno-noturna, e estão situados nas referidas ruas do Setor Central. Nestas, cada grupo de prostituição determina seu próprio território, defendendo-o, algumas vezes com certo grau de violência, da ameaça de invasão de outros tipos de atores sociais.

Durante a pesquisa com alguns garotos de programa, constatou-se, em Goiânia, a existência de duas áreas centrais para a disseminação da prostituição, ambas localizadas no Setor Central da cidade. Um dos entrevistados foi categórico em afirmar que não existe a escolha de determinado ponto fixo, mas apenas a escolha daquela região onde os acompanhantes se localizam, isto é, os acompanhantes não saem para outras regiões atrás de clientes; na verdade, são os clientes que vão até eles naquele território já delimitado pelo grupo. Isso corrobora a ideia de Ribeiro \& Mattos (1996), quando pontuam que os territórios dos michês são mais simbólicos, não existindo uma rigidez na escolha.

Os territórios da prostituição de rua tendem a ser volúveis, pois ora se ampliam, ora se reduzem, ocupando determinada porção de um espaço público. De certo modo, são móveis, pois não existe um limite estabelecido, sendo até instáveis, acompanhando os espaços de concreto, as praças e as ruas. Esse tipo de territorialização alterna-se habitualmente entre os períodos diurno e noturno (Souza, 1995).

Destaca-se aqui que, em Goiânia, por exemplo, ações envolvendo o Ministério Público, a Polícia Militar e outros órgãos procuram extinguir determinados locais de prostituição (Tavares, 2014).

A apropriação do território pela prostituição masculina vincula-se diretamente às limitações dos espaços dentro do cotidiano da sociedade, quais sejam: ruas, jornais, sites e aplicativos, tomados por grupos que promovem a territorialidade (Corrêa, 1995; Silva, 2009; Ornat, 2011). Antigamente, nas cidades brasileiras, a região que agrupava as atividades de prostituição e de boemia era chamada de zona. Nem sempre a zona comportava toda a prostituição da cidade, mas era o lugar mais conhecido e o de maior concentração (Andrade \& Teixeira, 2004).

No caso da prostituição, uma rua, um conjunto de ruas ou um lugar pode ser um território durante certo período de tempo. Isso ocorre porque o indivíduo ou um determinado grupo de pessoas, ao se apoderar de um local, formaliza um território. Esses pontos são delimitados simbolicamente pelos grupos e estão localizados em regiões, como nas ruas do centro da cidade, em jornais, sites e aplicativos, ou seja, as ruas e as mídias são utilizadas para a oferta do serviço de prostituição (Ribeiro \& Mattos, 1996; Haesbaert, 2014).

Existem alguns sites e aplicativos interativos que auxiliam na promoção do encontro de garotos e garotas de programa. Com relação aos garotos de programa, aplicativos, como o Grindr, permitem que eles postem fotos para quem realmente queira satisfazer seus desejos. Quando da utilização do Grindr, identificou-se a utilização de imagens apropriadas para destacar que aquele determinado indivíduo estava aberto para a venda do corpo para o sexo.

No Grindr, é possível verificar fotos do perfil e a descrição dos usuários, evidenciando uma similaridade com os anúncios de jornais. Um dos participantes entrevistados afirmou que faz uso desse aplicativo por ser bastante confiável. Durante a negociação, ele também pede foto do cliente. Além disso, não há custos, pois a ferramenta possui uma versão gratuita. Sendo assim, seus rendimentos são maiores. Outro aspecto importante levantado pelo participante foi o fato de que o aplicativo permite que a negociação seja mais segura. Nota-se que a migração desses serviços para a internet necessita ser mais pesquisada (Cardoso, 2014).

O uso de mídias alcança uma grande quantidade de pessoas, tendo eles poder de persuasão mediante a manipulação de sensações e de emoções. A publicidade veiculada pelas mídias permeia a comunicabilidade, trazendo a ideia de território oportuno para o processo de compra, ampliando, assim, suas fronteiras e rompendo barreiras territoriais móveis, simbólicas e culturais (Burgos, 2005; Burrowes, 2005; Haesbaert, 2014).

A multiterritorialidade promovida pela publicidade de anúncios estabelece uma relação de compra e venda, atraindo consumidores, com o objetivo de manipular seus desejos pessoais. Isso remete à ideia de territórios rugosos, os quais permeiam a ânsia e a voluptuosidade devidamente planejada, com vistas a atingir a essência emocional (Deleuze \& Guattari, 1997; Burrowes, 2005; Haesbaert, 2014).

Nota-se, portanto, que o estudo sobre territórios auxilia no preenchimento da lacuna encontrada nos estudos que estabelecem a relação entre território e gênero, com foco na prostituição masculina, e põe em evidência a inexistência de políticas públicas voltadas para as diferentes territorialidades de prostituição, especificadamente em Goiânia. 


\section{Território e corpo}

O Estado é responsável por distribuir os corpos pelos territórios; porém, alguns destes são ocupados sem a devida ordem, apenas pela facilidade de livre comércio ou acesso. Desse modo, a disposição dos sujeitos nos territórios de forma estratégica facilita o controle e a dominação do espaço, em suas formas de arranjar e rearranjar a sociedade com as regras do lugar (Lênin, 1983; Mondardo, 2009).

A ordenação e a segregação dos corpos nos territórios estão vinculadas às relações de autoridade, por uma ideologia de domínio da espécie humana, podendo ser simbólica, natural, cultural, econômica ou política. Isso significa um controle sobre algo volúvel, capaz de burlar a ordem imposta pelo Estado, devido à supervivência do grupo inserido naquele local, formando elementos específicos e princípios característicos - psicológicos, biológicos e sociais presentes no território e delimitados por fronteiras imaginárias, respeitando as relações persuasivas entre os grupos (Ribeiro \& Mattos, 1996; Mondardo, 2009; Haesbaert, 2014).

A ação sobre o corpo, o adestramento, a regulação do comportamento, a normalização do prazer, a interpretação do discurso, com o objetivo de separar, comparar, distribuir, avaliar, hierarquizar, tudo isso faz com que apareça pela primeira vez na história esta figura singular, individualiza - homem - como produção do poder (Foucault, 1985, p. 20).

0 corpo também é considerado um território essencialmente, o primeiro território, pois delimita seu local. Especificamente, no caso da prostituição, o próprio sexo também representa uma função de espaço - consequentemente, de território. Sua construção baseia-se em sentimentos afetivos e em relações de soberania e de poder sobre os seres humanos. Nota-se que corpo é um termo amplo devido à sua função e aos seus aspectos físico e lúdico, o que evidencia lugares e espaços (Boivin, 2012).

Por exemplo, existe uma exposição do território-corpo nos classificados de um grande jornal impresso de Goiânia, em que a construção divulgada remete à fantasia simbólica, com características específicas e exploração do desejo, o que induz à construção de imagens - corpos malhados e esculpidos - e aguça o imaginário dos clientes (Silva, 1994; Mondardo, 2009; Jornal 0 Popular, 2016).

Fica claro, portanto, que o corpo como território pode ser visto também por meio da configuração da identidade, moldando o estilo de vida e as diversas formas de caracterização do indivíduo - classe social e preferências (Castro, 2008).

\section{Considerações finais}

Em Goiânia, a trama para a construção dos territórios foi desmistificada por meio da apropriação de algumas áreas urbanas e mídias, que promovem as interações sociais entre os acompanhantes e os clientes. Com uma narrativa teórica, desbravando os conceitos de território, territorialidade, desterritorialidade, reterritorialidade, multiterritorialidade e microterritorialidade, vinculadas às concepções antropológicas, culturais, simbólicas e móveis, foi possível mapear os distintos territórios utilizados na pesquisa.

Nesta pesquisa, procedeu-se, inicialmente, a uma revisão bibliográfica sobre prostituição masculina e territórios. Realizaram-se também entrevistas com garotos de programas, com o objetivo de entender a concepção imaginária desses indivíduos, bem como seu território econômico - o comércio do sexo. Ademais, procedeu-se ao levantamento das dimensões espaciais dos territórios fixos, onde se instalam os acompanhantes do Setor Central em Goiânia, identificando o quadrilátero da região compreendida entre as ruas 2, 8, 3 e 7 (DM, 2016; Jornal O Popular, 2016).

Verificou-se que a movimentação no Setor Central da cidade se dá entre os pontos móvel e simbólico. Observou-se também que o território fixo ocorre durante horários não comerciais, ou seja, no período noturno. Além disso, foram identificados mecanismos que concebem territórios fixos nas mídias - jornais, sites e aplicativos - , que promovem a divulgação de território - nesse caso, o corpo.

Esta pesquisa abordou a transição do tema território da prostituição masculina, o que, evidentemente, não esgota o assunto. Nota-se, de um lado, a mobilidade dos indivíduos, rompendo barreiras por meio das mídias; de outro, o aspecto físico, porém simbólico, daqueles que utilizam territórios volúveis, sendo estes destinados, no período diurno, ao comércio, transformando-se, no período noturno, em novos 
territórios, agora com acesso real ou virtual, permitindo também o estabelecimento de relações comerciais.

Diante do que foi apresentado, conclui-se que os territórios promovem a migração, o desenraizamento, o rompimento de fronteiras para um mundo e suas virtualidades, em uma nova relação de entendimento das diversas formas de divulgação e de comercialização do território-corpo.

\section{Referências}

Andrade, A. C. (1994). Terriorialidades, desterritorialidades, novas territorialidades: os limites do poder nacional e do poder local. In M. Santos, M. A. A. Souza, \& M. L. Silveira (Eds.), Território: globalização e fragmentação. São Paulo: Hucitec.

Andrade, L. T., \& Teixeira, A. E. (2004). A territorialidade da prostituição em Belo Horizonte. Cadernos Metrópole, $11,137-157$.

Barreto, R. C. V. (2008). Território e preconceito: um olhar sobre o erritório e preconceito: um olhar sobre o território de convivência homossexual da território de convivência homossexual da Farme de Amoedo. Caderno Espaço Feminino, 20(2), 251-266.

Barthe-Deloizy, F. (2011). Le corps peut-il être un objet du savoir géographique? Ou comment interroger le corps pour mieux comprendre l'espace des sociétés? Géographie et Cultures, 80(80), 229-247. http://dx.doi.org/10.4000/ gc.544.

Boivin, N. (2012). Territoires hédonistes du sexe: pour une géographie des subjectivations. Géographie et Cultures, 83(83), 87-100. http://dx.doi.org/10.4000/gc.2068.

Brasil. (1943, 9 de agosto). Decreto-lei $n^{\circ}$ 5.452, de 1 de maio de 1943. Aprova a consolidação das leis do trabalho. Brasília: Diário Oficial da União.

Brasil. (2002, 10 de janeiro). Lei no 10.406 , de 10 de janeiro de 2002. Institui o Código Civil. Brasília: Diário Oficial da União.

Braz, S. (2011). Prostituição feminina: história e territorialidades no espaço urbano de Teresina. Recuperado em 20 de novembro de 2017, de https://geografiaespaçotempoecultura. wordpress.com
Burgos, M. B. (2005). Cidade, territórios e cidadania. Dados: Revista de Ciências Sociais, 48(1), 189-222. http://dx.doi. org/10.1590/S0011-52582005000100007.

Burrowes, P. (2005). Viagem ao território da publicidade. Revista Comunicação Mídia e Consumo, 2(5), 205-219.

Cardoso, C. (2014, 28 de outubro). Não tá fácil para ninguém: internet afetando a mais antiga das profissões. Meio Bit. Recuperado em 9 de abril de 2016, de http:// meiobit.com/301707/tinderegrindrameacaaprostituicao/

Castro, A. L. (2008). O corpo como território de construção de identidades na cultura contemporânea. Brasília: ABANT. Recuperado em 9 de agosto de 2016, de http://www.abant. org.br/conteudo/ANAIS/CD_Virtual_26_RBA/grupos_de_ trabalho/trabalhos/GT\%2030/Ana\%20L\%C3\%BAcia.pdf

Castro, E. (2009). Vocabulário de Foucault. Belo Horizonte: Autêntica.

Corrêa, R. L. (1994). Territorialidade e corporação: um exemplo. In M. Santos, M. A. A. Souza, \& M. L. Silveira (Eds.), Território: globalização e fragmentação. São Paulo: Hucitec.

Corrêa, R. L. (1995). Espaço, um conceito chave da Geografia. In I. E. Castro, P. C. C. Gomes, \& R. L. Corrêa (Eds.), Geografia: conceitos e temas. Rio de Janeiro: Bertrand Brasil.

Deleuze, G.; Guattari, F. (1997). Mil platôs, capitalismo e esquizofrenia. São Paulo: Editora 34.

Diário da Manhã - DM. (2015). Projeto Picnik chega a Goiânia. Recuperado em 21 de setembro de 2016, de http://www.dm.com.br/cultura/2015/07/projeto-picnikchega-a-goiania.html

Dicionário Michaelis. (2009). Definição rua. Recuperado em 30 de março de 2016, de http://michaelis.uol.com.br/ moderno/portugues/definicao/rua\%20_1039385.html

Ferreira, N. S. (2002). As pesquisas denominadas estado da arte. Education et Sociétés, 23(79), 257-272. http:// dx.doi.org/10.1590/S0101-73302002000300013.

Figueiredo, G. O., Brito, D. T. S., \& Botazzo, C. (2003). Ideologia, fetiche e utopia na saúde: uma análise a partir da saúde bucal. Ciência \& Saúde Coletiva, 8(3), 753-763. http://dx.doi.org/10.1590/S1413-81232003000300009.

Flores, M. (2006). A identidade cultural do território como base de estratégias de desenvolvimento: uma visão do estado da arte. Contribuição para o Projeto Desenvolvimento Territorial Rural a partir de Serviços e Produtos com Identidade - RIMISP. Recuperado em 14 de setembro 
de 2016, de http://camara.fecam.org.br/uploads/28/ arquivos/4069_FLORES_M_Identidade_Territorial_como_ Base_as_Estrategias_Desenvolvimento.pdf

Fortuna, C. (2012). (Micro) territorialidades: metáfora dissidente do social. Terr@Plural, 6(2), 199-214.http:// dx.doi.org/10.5212/TerraPlural.v.6i2.0001.

Foucault, M. (1985). Microfísica do poder (5a ed.). Rio de Janeiro: Graal.

Foucault, M. (2008). Segurança, território, população: curso dado no College de France (1977-1978). São Paulo: Martins Fontes.

Gehlen, I., \& Riella, A. (2004). Dinâmicas territoriais e desenvolvimento sustentável. Sociologias, 6(11), 20-26. http://dx.doi.org/10.1590/S1517-45222004000100003.

Geiger, P. P. (1994). Des-territorialização e espacialização. In M. Santos, M. A. A. Souza, \& M. L. Silveira (Eds.), Território: globalização e fragmentação. São Paulo: Hucitec.

Goffman, E. (2010). Comportamentos em lugares públicos. Petrópolis: Vozes.

Goiás. Secretaria de Estado de Gestão e Planejamento SEGPLAN. (2013). Plataforma logística multimodal de Goiás. Audiência pública. Recuperado em 20 de novembro de 2017, de http://www.sgc.goias.gov.br/upload/arquivos/2013-11/ plataforma-logistica-multimodal-degoias_audienciapublica_vf.pdf

Gondim, G. M. M., \& Monken, M. (2008). Territorialização em saúde. In I. B. Pereira, \& J. C. F. Lima (Eds.), Dicionário da educação profissional em saúde (2a ed.). Rio de Janeiro: EPSJV.

Guattari, F. (1990). As três ecologias. Campinas: Papitus.

Haesbaert, R. (2004). O mito da desterritorialização: do fim dos territórios à multiterritorialidade. Rio de Janeiro: Bertrand Brasil.

Haesbaert, R. (2014). O mito da desterritorialização: do "fim dos territórios" à multiterritorialidade (8a ed.). Rio de Janeiro: Bertrand Brasil.

Harvey, D. (2001). Spaces of capital: towards a critical geography. New York: Routledge.

Henrique, W. (2009). O direito à natureza na cidade. Salvador: EDUFBA. http://dx.doi.org/10.7476/9788523209117.
Ianni, O. (1988). A questão nacional na América Latina. Estudos Avançados, 2(1), 5-40. http://dx.doi.org/10.1590/ S0103-40141988000100003.

Jornal O Popular. (2016). Jornal Classificados (Vol. 78, No. 22908, pp. 7). Goiânia.

Lênin, V. I. (1983). O estado e a revolução: o que ensina o marxismo sobre o estado e o papel do proletariado na Revolução. São Paulo: Hucitec.

Marx, K., \& Engels, F. (1980). A ideologia alemã (4a ed.). Portugal: Editorial Presença.

Medeiros, M. (1999). Olhando a lua pelo mundo da rua: representações sociais da experiência de vida de meninos em situação de rua (Tese de doutorado). Universidade de São Paulo, Ribeirão Preto. Recuperado em 5 de abril de 2016, de http://www.teses.usp.br/teses/disponiveis/83/83131/ tde-25022003-082739/pt-br.php

Mondardo, M. L. (2009). O Corpo enquanto "Primeiro" Território de Dominação: o biopoder e a sociedade de controle. Recuperado em 9 de agosto de 2016, de http:// www.bocc.ubi.pt/pag/mondardo-marcos-o-corpo.pdf

Neves, G. R. (1994). Territorialidade, desterritorialidade, novas territorialidades (algumas notas). In M. Santos, M. A. A. Souza, \& M. L. Silveira (Eds.), Território: globalização e fragmentação. São Paulo: Hucitec.

Oliveira, J. C. (1998). A casa e a rua: frutos do trabalho social ou local de dominação? Boletim Goiano de Geografia, 18(1), 47-62. Recuperado em 16 de setembro de 2016, de https://revistas.ufg.br/bgg/article/view/4288/3762

Ornat, M. J. (2011). Território descontínuo e multiterritorialidade na prostituição travesti no sul do Brasil (Tese de doutorado). Programa de Pós-graduação em Geografia, Universidade Federal do Rio de Janeiro, Rio de Janeiro. Recuperado em 12 de agosto de 2016, de http://www.gete.net.br/joomla/ attachments/article/77/Projeto\%20de\%20TESE.pdf

Pompei, C. S. et al. (2014). Estudio multidisciplinario del ecosistema manglar en la comunidad tradicional de Curral Velho. Barcelona: Institut de Ciència I Tecnologia Ambientals, UAB.

Raffestin, C. (1987). Repères pour une théorie de la territorialité humaine. Cahier/Groupe Réseaux, 3(7), 263279. Recuperado em 16 de setembro de 2017, de http:// www.persee.fr/doc/flux_1162-9630_1987_num_3_7_1053

Raffestin, C. (1993). Por uma geografia do poder (Trad. Maria Cecília França). São Paulo: Ática. 
Reis, J. (2015). Território e políticas do território: a interpretação e a ação. Finisterra, 1(100), 107-122. Recuperado em 20 de novembro de 2017, de http://www. scielo.mec.pt/pdf/fin/n100/n100a10.pdf

Ribeiro, M. A. C., \& Mattos, R. B. (1996). Territórios da prostituição nos espaços públicos da área central do Rio de Janeiro. Revista Território, 1(1), 60-76. Recuperado em 14 de setembro de 2016, de http://www.revistaterritorio. com.br/pdf/01_6_ribeiro_\%20mattos.pdf

Sack, R. (1986). Human territoriality. Cambridge: Cambridge University Press.

Santos, M., Souza, M. A., \& Silveira, M. L. (1994). Território: globalização e fragmentação. São Paulo: Hucitec.

Saquet, M. A. (2007). Abordagens e concepções de território (Coleção Geografia em Movimento). São Paulo: Expressão Popular.

Silva, A. C. (1994). 0 território da consciência e a consciência do território. In M. Santos, M. A. A. Souza, \& M. L. Silveira (Eds.), Território: globalização e fragmentação. São Paulo: Hucitec.

Silva, J. M. (2009). Ausências e silêncios do discurso geográfico brasileiro: uma crítica feminista à geografia eurocêntrica. In J. M. Silva (Ed.), Geografias subversivas: discursos sobre espaço, gênero e sexualidade. Ponta Grossa: Todapalavra.

Souza, M. L. (1995). 0 território: sobre espaço e poder, autonomia e desenvolvimento. In I. E. Castro, P. C. C. Gomes, \& R. L. Corrêa. Geografias: conceitos e temas. Rio de Janeiro: Bertran Brasil.

Souza, T. P., \& Carvalho, S. R. (2014). Apoio territorial e equipe multirreferencial: cartografias do encontro entre o apoio institucional e a redução de danos nas ruas e redes de Campinas, SP, Brasil. Interface: Comunicação e Saúde Educacional, 18(Supl 1), 945-956. http://dx.doi. org/10.1590/1807-57622013.0518.

Tavares, M. (2014, 26 de janeiro). O Mapa da prostituição na Grande Goiânia. Goiânia: Diário da Manhã.

Vilela, B. P. (2009). Interpretação das paisagens culturais na Bacia Hidrográfica do rio caldas: uma proposta de princípios para ações em educação ambiental sustentada (Dissertação de mestrado). Programa de Pós-graduação em Geografia, Universidade Federal de Goiás, Goiânia.

Recebido: Fev. 07, 2017

Aprovado: Out. 17, 2017 